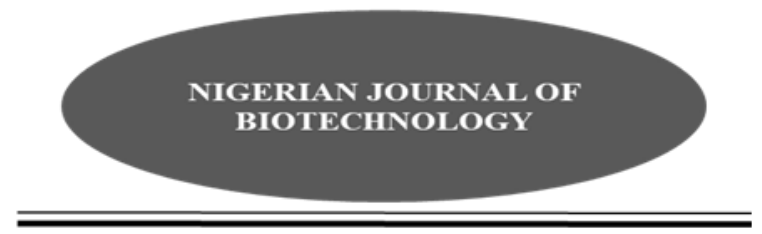

\title{
Prevalence Of Extended Spectrum Beta-Lactamases (ESBLs)- Producing Escherichia Coli Isolated From UTI Patients Attending some Selected Hospitals In Minna, Nigeria
}

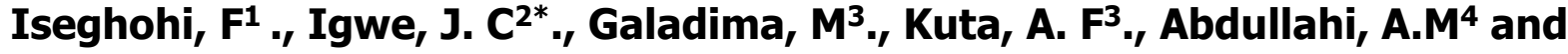 \\ Chukwunwejim. C.R ${ }^{5}$. \\ ${ }^{1}$ Department of Medical Biotechnology, National Biotechnology Development Agency, Abuja \\ ${ }^{2}$ Department of Pharmaceutical Microbiology and Biotechnology, Kaduna State University \\ ${ }^{3}$ Department of Microbiology Federal University of Technology Minna \\ ${ }^{4}$ Deptartment of Medicine, Infectious and Tropical Diseases Unit, Ahmadu Bello University Teaching \\ Hospital, Zaria \\ ${ }^{5}$ Deptartment of Pharmaceutical Microbiology and Biotechnology, Nnamdi Azikiwe University, Awka
}

\begin{abstract}
Globally, urinary tract infections are one of the most common infections in need of urgent clinical attention. The prevalence of extended spectrum beta-lactamases (ESBL)producing Escherichia coli isolated from urine samples of some UTI patients and $s$ of apparently healthy individuals in Minna, Nigeria, is investigated. Standard microbiological techniques were used to conduct this study. A total of $\mathbf{1 7 0}$ catch midstream urine samples submitted to the Medical Microbiology Laboratories of 4 different hospitals (and samples from healthy individuals) were randomly collected for 5 months and examined for microbial growths. Female patients $(65.9 \%)$ submitted more urine samples for UTI test than their male counterpart (34.1\%). The age ranges of $21-30(26.5 \%)$ and $31-40(25.3 \%)$ had the highest percentages of infection rate while those within the ages $1-10$ (3.5\%) and $\geq 71(2.3 \%)$ were the least infected. This study observed a prevalence of $23.5 \%$ of $E$. coli in Minna metropolis and a significant number $(30 \%)$ of healthy individuals (HI) was observed to harbor the $E$. coli in their urine. The isolates were highly susceptible to Gentamicin (65\%), Ofloxacin (65\%), Tetracycline $(62.5 \%)$, Cotrimoxazole (62.5\%), and Streptomycin (57.5\%). Mildly susceptible to Pefloxacin $(37.5 \%)$, Chloramphenicol (37.5\%), and Ciprofloxacin $(35 \%)$. There were significant resistance to most of the beta-lactames tested [Cefuroxime ( $80 \%)$, Amoxicillin (42.5\%), Augmentin (40), Cefotaxime (20\%) and Ceftaxidime (7.5\%)]. Two of the isolates were resistant to all the 13 antibiotics tested; $70 \%$ (28) of the isolates had multiple antibiotics resistance index (MARI) 20.3 . Multidrug resistance was expressed in $37.5 \%$ of the isolates tested. The study showed a vast resistant pool in the environment. Only $25 \%$ of the $E$. coli isolated from the urine samples produced beta-lactamases phenotypically, most of which expressed resistance to more than $\mathbf{5}$ of the antibiotics tested and had MARI of $\geq 0.5$. Further evaluation showed that $25 \%(10 / 40)$ of the $E$. coli isolated from the UTI patients in Minna, Nigeria, were ESBL- producers and could harbor one or two of the genes. TEM gene was expressed in $70 \%$ (7) of the isolates that produced ESBL phenotypically, $60 \%$
\end{abstract}


Isegohi et al./ Nig. J. Biotech. Vol. 37 Num. 2: 56-73 (Dec 2020)

(6) harbored CTXM gene, $20 \%$ (2) had the OXA gene while none of the bacteria harbored the SHV gene. The study established a 5.9\% ESBL prevalence among the $E$. coli isolated from UTI in the environment studied. This study established that $E$. coli is one of the prevalent bacteri urea majorly isolated from UTI patients in Minna. The prevalent $E$. coliare multidrug resistant and could harbor more than one ESBL gene.

\section{Corresponding Author: igwejames42@yahoo.com Introduction}

keywords: Escherichia coli, Minna, UTI, ESBL, Multidrug resistance

Different studies have defined urinary tract infections (UTIs) as the growth of pathogenic microorganisms in the urinary tract, which might elicit inflammatory disorders resulting in burning sensations while urinating, increase in temperature, dysuria, itching, pain around the pelvic region, development of wounds and inflammation of the genital area, genital and suprapubic pain, and in some cases permanent kidney damage (Prakash and Saxena, 2013; Hoberman et al., 2003). UTIs can result in cystitis, an infection of the upper urinary tract that includes the urethras, renal pelvis and kidneys and pyelonephritis, an infection of the lower urinary tract that includes the infection of urethra and urinary bladder (Lane and Takhar, 2011). With respect to frequency of occurrence of bacteria in UTI, Escherichia coli, Staphylococcus, Klebsiella pneumoniae, Proteus, Pseudomonas, Enterococc us, and Enterobacter are the most implicated agents (Mirsoleymani et al., 2014).

Urogenital anomalies occur in individuals who retain urine longer than expected in their bladder (Dougherty and Rawla, 2020). Studies have shown that pregnant women with inflamed intraamniotic balloons, which result to overdistention of the uterus are prone to pyelitis and pyelonephritis with severe consequences (Sani et al., 2019). Martin, et al., (2019) demonstrated that age groups $\leq 19$ years and the elderly, female gender, married individuals, patients with genitourinary tract abnormalities, diabetes, hospitalized patients and those with indwelling catheter $>6$ days are susceptible to high microbial proliferation in their urinary tracts. Factors such as patients residence, tribe, level of education, marital status, circumcision, pregnancy, hypertension, HIV, abortion, sexual intercourse had no correlation with UTI but can contribute to reinfection. According to the CDC, (2019), within 3 months of birth, male children have more probability of contracting UTI while females become more vulnerable thereafter. UTI could be community acquired or hospital acquired (nosocomial) and expressed in patients as acute, chronic, complicated or uncomplicated and in some cases asymptomatic, depending on an individual's immune status (Nelson and Good, 2015). Other factors of importance in cases associated with UTI are malnutrition, poor hygiene and low socio-economic status, which are common in rural settings (Ahmed \& Avasara, 2008). The clinical symptoms of this disease vary depending on the sites of infection, the causative organisms, pregnancy, the severity of the infection and the age of the infected patients (Dias et al., 2010). In 2019, Sani et al., had reported that $E$. coli was the most predominant organism causing UTI in Minna (27.3\% prevalence) and females (27.9\%) are the most infected. This is followed by Staphylococcus aureus (24.6\%) and Pseudomonas species $(1.3 \%)$ being the least. According to Pandit et al., (2020), treatment of UTI is becoming difficult due to the emergence, reemergence and spread of multidrug-resistant uropathogens encoding extended-spectrum $\beta$-lactamases (ESBLs), which are plasmid mediated. Extended spectrum beta lactamases (ESBLs) are class A $\beta$-lactamases produced by the Enterobacteriaceae family of Gram-negative organisms that hydrolyze penicillin, oxyimino-cephalosporins, and monobactams but not cephamycins or carbapenems (Mehrgan and Rahbar, 2008). These types of enzymes are inhibited in vitro by clavulanate (Lohani et al., 2020). The most prevalent genes of ESBLs are CTX-M types, TEM, OXA and SHV (Abrar et al., 2019). Other clinically important genes include VEB, PER, BEL-1, BES-1, SFO-1, TLA, and IBC (Jacoby and Munoz-Price, 2005; Falagas and Karageorgopoulos, 2009; Dhillon and Clark, 2012). These genes evolve in bacteria that develop resistance to antibiotics majorly prescribed in an environment 
(Lohani et al., 2020). These studies further showed that antibiotics such as imipenem, gentamycin and nitrofurantoin are the best drugs for the treatment of infections linked to ESBLproducing $E$ coli isolates from UTI. Study conducted by Baziboroun et al., (2018) further substantiates the fact that high percentage of the UTI isolates did express significant levels of resistance against ceftazidime, cefotaxime, ceftriaxone, cefixime and ciprofloxacin, ranging from $61-100 \%$, while the highest percentage of susceptibilities were observed against meropenem, piperacillin- tazobactam (100\%), followed by nitrofurantoin and amikacin (91\%). These studies show vast resistance to betalactams while other studies have isolated fluoroquinolone-resistant uropathogens $(\mathrm{Wu}$, et al., 2014), carbapenem-resistant Enterobacteriaceae, (Schechner, et al., 2013) and vancomycin-resistant Enterococci (PapadimitriouOlivgeris, et al., 2014) among UTI patients. This might be linked to factors such as misuse of antibiotics in the society and poultries, reexposure of infected patients, acquisition of plasmid mediated ESBL genes, use and administration of drugs without appropriate culture and sensitivity tests for asymptomatic and mildly symptomatic UTI patients (Igwe et al., 2014). This study was hence designed to evaluate the prevalence of $E$. coli in UTI in Minna, investigate the antimicrobial susceptibility patterns of selected antibiotics and also assay for the presence of ESBL.

\section{Materials and Methods}

\section{Study Area}

Samples were collected from the Medical microbiology laboratories of four hospitals within Minna metropolis: General Hospital, Minna; Ibrahim Badamosi Babangida (IBB) Specialist Hospital, Chanchaga; Top Medical Clinic, Tunga and Standard Hospital, Old airport road. The Map showing the locations of the Four Hospitals in Minna Metropolis, Niger State as captured by Google Earth Image, (2016) is shown below, represented in yellow colour.

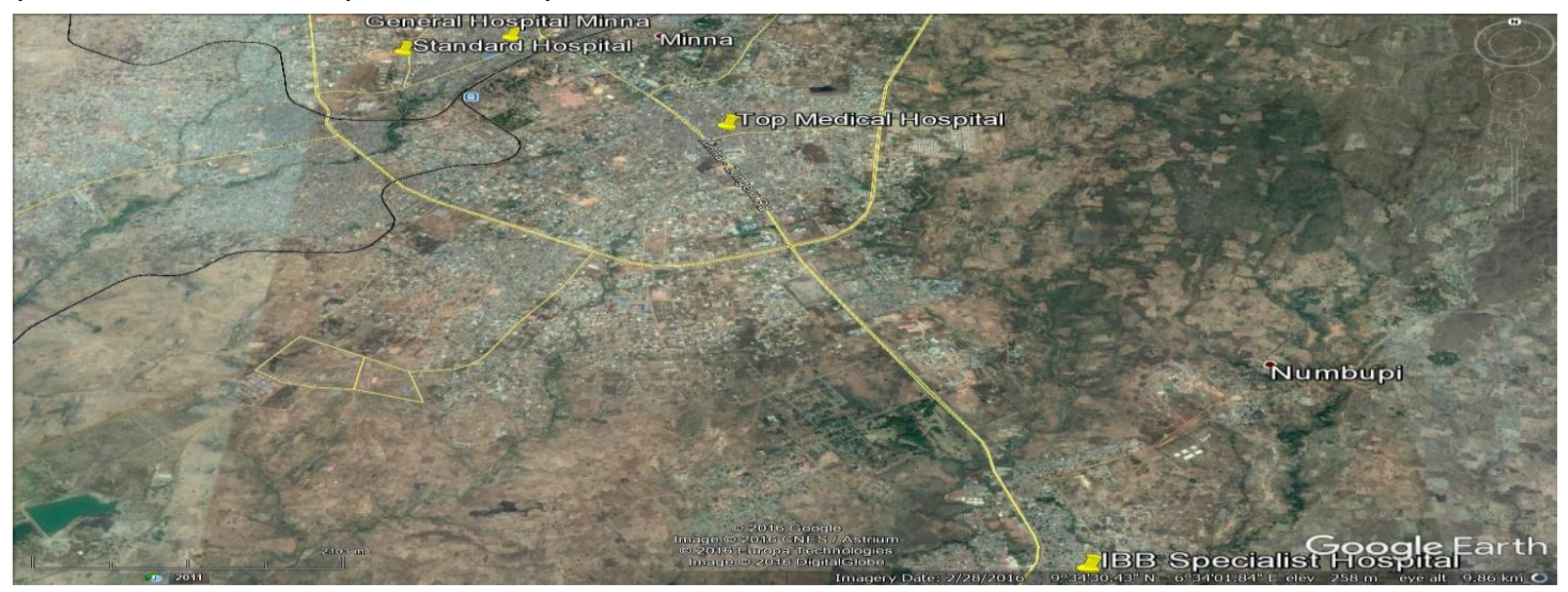

Figure 1: Locations of the Four Hospitals in Minna Metropolis, Niger State

\section{Determination of Sample Size}

The sample size was determined using the single proportion method and prevalence of $12.3 \%$ as reported by Jombo et al., (2006a).

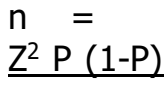

$\mathrm{D}^{2}$
Where $n=$ sample size

$Z=1.96$ for Confidence level at $95 \%$

$\mathrm{P}=$ Prevalence rate at $12.3 \%$

$D=0.05$ for Marginal error at $5 \%$ The sample size was calculated as 165 , which was rounded up to 170 . 


\section{Ethical Clearance}

Approval for this study was obtained from the Ethical Committee of the General Hospital, Minna, Niger State with the registration number HMB/GHM/STA/136/VOL.II/350, dated $29^{\text {th }}$ October, 2015.

\section{Specimen Collection and Processing}

A total of 170 samples of clean-catch midstream urine submitted to the Microbiology Laboratory of the four hospitals in Minna metropolis and 20 samples from healthy individuals were randomly collected within the period of 5 months (May September, 2015). The samples were transported to the Microbiology Department laboratory, Federal University of Technology (F.U.T), Minna in an ice pack within 40 minutes of collection for further analysis.

\section{Isolation and Identification of Escherichia coli}

The $E$. coli isolates were identified and characterized based on their morphological characteristics, culture, metabolic fermentation, Gram's reaction and other biochemical reactions such as indole, methyl red, Voges-Proskauer, urease, citrate utilization, triple sugar iron, motility and lysine decarboxylase tests as described by Cheesbrough (2010).

Antibiotic Susceptibility Test
The confirmed $E$. coli isolates were subjected to antibiotic sensitivity tests against thirteen (13) commonly prescribed antibiotics being used in treating infections caused by $E$. coli. This test was determined according to CLSI (2006) and Cheesbrough (2010). An overnight broth culture of each isolate was inoculated on nutrient agar and incubated at $37^{\circ} \mathrm{C}$ for $24 \mathrm{~h}$. 0.5 McFarland turbidity standard was prepared for standardization of inoculums $\left(1.5 \times 10^{8} \mathrm{cfu} / \mathrm{ml}\right)$. McFarland turbidity standard solution (0.5) was prepared by combining $1 \%$ solution of anhydrous barium chloride $\left(\mathrm{BaCl}_{2}\right)$ and $1 \%$ solution of sulfuric acid ( $\mathrm{H} 2 \mathrm{SO} 4)$, mixed thoroughly to form a turbid solution. Using a sterile wire loop 35 well-isolated colonies of similar appearance from nutrient agar were emulsified in the $5 \mathrm{ml}$ sterile saline in a test tube. In a good light match, the turbidity of the suspension was compared to the turbidity standard of $0.5 \mathrm{McFarland}$ and the suspensions were then inoculated on Mueller Hinton agar at angle $60^{\circ}$ across the plate using a sterile cotton swab to ensure even distribution and confluent growth. The plates were further allowed to dry for 5 minutes with the plates closed before placing the discs. Furthermore, the plates were exposed to an $18 \mathrm{~h}$ incubation period at $37^{\circ} \mathrm{C}$ after a 15 minutes pre-diffusion time. Afterwards, the size of the zones of inhibition were examined and interpreted using the CLSI (2016) (Tab. 1).

Table 1: Clinical Laboratory Standard Institute Interpretation for some Selected Antibiotics

S/N Beta Lactam Antibiotics Zone of Inhibition ( $\mathrm{mm}$ )

\begin{tabular}{lllll} 
& & Susceptible & Intermediate & Resistance \\
\hline 1 & Ceftazidime $(30 \mu \mathrm{g})$ & $\geq 18$ & $15-17$ & $\leq 14$ \\
2 & Cefotaxime $(30 \mu \mathrm{g})$ & $\geq 23$ & $15-22$ & $\leq 14$ \\
3 & Cefuroxime $(30 \mu \mathrm{g})$ & $\geq 18$ & $15-17$ & $\leq 14$ \\
4 & Amoxicillin $(30 \mu \mathrm{g})$ & $\geq 17$ & $14-16$ & $\leq 13$ \\
5 & Amoxicillin-clavulanic acid $(10 / 20 \mu \mathrm{g})$ & $\geq 18$ & $14-17$ & $\leq 13$ \\
6 & Cotrimoxazole $(7 / 23 \mu \mathrm{g})$ & $\geq 16$ & $11-15$ & $\leq 10$
\end{tabular}


Isegohi et al./ Nig. J. Biotech. Vol. 37 Num. 2: 56-73 (Dec 2020)

\begin{tabular}{lllcc}
7 & Chloramphenicol $(30 \mu \mathrm{g})$ & $\geq 18$ & $13-17$ & $\leq 12$ \\
8 & Tetracycline $(30 \mu \mathrm{g})$ & $\geq 15$ & $12-14$ & $\leq 11$ \\
9 & Ciprofloxacin $(5 \mu \mathrm{g})$ & $\geq 21$ & $16-20$ & $\leq 15$ \\
10 & Gentamicin $(10 \mu \mathrm{g})$ & $\geq 15$ & $14-15$ & $\leq 12$ \\
11 & Streptomycin $(30 \mu \mathrm{g})$ & $\geq 15$ & $12-14$ & $\leq 11$ \\
12 & Perfloxacin $(10 \mu \mathrm{g})$ & $\geq 21$ & $16-20$ & $\leq 15$ \\
13 & Ofloxacin $(10 \mu \mathrm{g})$ & $\geq 16$ & $13-15$ & $\leq 12$ \\
\hline
\end{tabular}

\section{Determination of Multiple Antibiotic Resistance (MAR) Index}

The MAR index of each of the $E$. coli isolates was evaluated according to Krumperman (1983).

MAR Index $=\underline{\text { Number of Antibiotics }}$ to which the isolate is resistant to

of Antibiotics tested

Total number

Presumptive Test for Extended Spectrum Beta Lactamase (ESBL) Production

The double disc synergy test described by Dechen et al., (2009) was used to confirm ESBL production among the $E$. coli isolates. $E$. coli isolates that harbored multidrug resistant characteristics were standardized in phosphate normal saline using 0.5 McFarland turbidity standard. A $24 \mathrm{~h}$ broth culture of the isolates were streaked on nutrient agar and incubated at $37^{\circ} \mathrm{C}$ for another $24 \mathrm{~h}$. 0.5 McFarland turbidity standard solution was prepared for standardization of inoculums. With the help of a sterile wire loop, 5 good identical colonies from nutrient agar were introduced into $5 \mathrm{ml}$ sterile normal saline in a test tube and its turbidity compared to 0.5 McFarland standard. The admixture was then streaked on already prepared Mueller Hinton Agar (MHA). Using a sterile pair of forceps, antibiotic disk containing amoxicillin-clavulanate $(20 \mu \mathrm{g} / 10 \mu \mathrm{g})$ was placed in the center of the plate, and ceftazidime $(30 \mu \mathrm{g})$, cefotaxime $(30 \mu \mathrm{g})$, and cefuroxime $(30 \mu \mathrm{g})$ each were placed $20 \mathrm{~mm}$ from the amoxicillinclavulanate disk at the center. The MHA plate was incubated at $37^{\circ} \mathrm{C}$ for $24 \mathrm{~h}$. For standard control, E. coli ATCC 25922 typed culture which is a recommended reference strain for detection of ESBL production was used (CLSI, 2016). An increase in the zone diameter towards amoxicillin-clavulanic acid implies ESBL production or isolates that showed a distinct shape/size with potentiation towards amoxicillin clavulanic disc and a $\geq 5 \mathrm{~mm}$ increase in size for most of the drugs tested compared to when tested alone is an indication for ESBL production.

Molecular Characterization of Extended Spectrum Beta Lactamase Resistant Escherichia Coli

\section{Bacterial Cell Preparation}

The method of Dubey (2009) was used in preparing the bacterial cells for molecular analysis. Luria and Bertani broth medium were prepared by dissolving $10 \mathrm{~g}$ of peptone water, $5 \mathrm{~g}$ of $\mathrm{NaCl}, 10 \mathrm{ml}$ of $1 \mathrm{~N} \mathrm{NaOH}, 5 \mathrm{~g}$ of yeast extract in 1litre of distilled water. The $\mathrm{pH}$ of the solution was increased to 7.0 using $\mathrm{NaOH}$ solution and autoclaved. Five overnight cultured identical colonies of the resistant $E$. coli isolates were 
transferred into $5 \mathrm{ml}$ Luria and Bertani (LB) broth and incubated for 24h. Using an Eppendorff's tube, bacteria cells were then harvested by centrifugation at $4^{\circ} \mathrm{C}, 8000 \mathrm{rpm}$ in a refrigerated centrifuge for 30 seconds and the supernatants decanted.

\section{DNA Extraction}

DNA extraction was performed using Bioneer Accuprep $\AA$ GMO DNA Extraction Kit following the manufacturer's instructions as follows. Bacteria cell suspension in Luria broth was centrifuged at 6000rpm for 1 minute and cell pellets harvested. The pellets were re suspended in $200 \mu \mathrm{l}$ of phosphate-buffered saline (PBS) and transferred to a falcon tube containing $20 \mu$ l of Proteinase $K$ and vortexed for 10 secs. Thereafter, the tubes were put in a water bath for $10 \mathrm{mins}$ at $55^{\circ} \mathrm{C}$ to lyse the cells. One hundred microlitre $(100 \mu \mathrm{l})$ of absolute ethanol was added to the suspension in the tubes and allowed to stand for 2 mins. Using a pipette, $600 \mu \mathrm{l}$ of sample (cell lysate) was transferred from the tube into the binding column and centrifuged at $8000 \mathrm{rpm}$ for $1 \mathrm{~min}$. Supernatant was discarded and the binding column was transferred into another binding column. Five hundred microlitre (500) $\mu$ l of washing buffer 1 was added and centrifuged for 2 minutes at $8000 \mathrm{rpm}$. Supernatant was discarded and the binding column was transferred into another column and $500 \mu \mathrm{l}$ of washing buffer 2 was added and centrifuged at
8000 rpm for 1 minute. The column was removed and the supernatant discarded. The binding column was centrifuged again at 13000rpm (to remove excess water, ethanol). About $50 \mu \mathrm{l}$ of an elution buffer was added to the binding column and left for $1 \mathrm{~min}$ after which it was centrifuged at $10000 \mathrm{rpm}$ for $2 \mathrm{~min}$ (so that the dissolved DNA flows down to the bottom of the binding column). Extracted DNA was suspended in the elution buffer for further use and preservation (Bioneer Accuprep ${ }^{\circledR}$ GMO DNA Extraction Kit Manual, 2012).

Detection and Characterization of Resistant Genes Using Polymerase Chain Reaction (PCR)

Polymerase chain reaction (PCR) amplification of target genes from isolated plasmid DNA was carried out. Primers which are specific for ESBL genes were used for the PCR amplification (Table 2). This was conducted using Dream $\mathrm{Taq}^{\mathrm{TM}} \mathrm{PCR}$ master mix (2x), after thawing from ice and centrifuged at $10,000 \mathrm{rpm}$ for 30 seconds. An eppendorf tube was placed on an ice and the following components were added to make up $50 \mu$ l volume reaction: $25 \mu$ l of Dream Taq $^{\mathrm{TM}}$ PCR master mix, $1.0 \mu \mathrm{l}$ of the forward primer, $1.0 \mu \mathrm{l}$ of the reverse primer, $10.0 \mu$ l of template DNA (plasmid DNA) and $13 \mu \mathrm{l}$ nuclease free water. The admixture was vortexed and spun down, while the conditions in Table 3 were adopted for the PCR.

Table 2: Extended Spectrum Beta lactamases Primers

The nucleotide sequence of the primers and base pair of each of the ESBL genes is stated below.

\begin{tabular}{llll}
\hline Gene & \multicolumn{1}{c}{ Sequence } & $\begin{array}{c}\text { Amplicon } \\
\text { Size (bp) }\end{array}$ & Reference \\
\hline SHV & F: 5 ' GCCGGGTTATTCTTATTTGTCCG3' & 868 & Igwe et al. (2014) \\
& R:5' ATGCCGCCGCCAGTCA3' & & \\
TEM & F: 5 'ATTCTTGAAGACGAAAGGGCCTC3' & 931 & Igwe et al.(2014) \\
& R: $5^{\prime}$ 'TTGGTCTGACAGTTACCAATGC3' & & Monstein et al. (2007) \\
CTX-M & F: 5 ' CGCTTTGCGATGTGCAG3' & 593 &
\end{tabular}


Isegohi et al./ Nig. J. Biotech. Vol. 37 Num. 2: 56-73 (Dec 2020)

OXA

F:5 ' AAGAAACGCTACTCGCCTGC3'

478

Igwe et al.(2014)

R: 5 ' CCACTCAACCCATCCTACCC3'

Key: SHV (Sulfhydryl variable), TEM (Temoneira), CTX-M (Cefotaxime hydrolyzing), OXA (Oxacillin hydrolyzing), bp (base pair), A (Adenine), C (Cytosine), T (Thymine), G (Guanine)

Table 3: PCR Thermal Cycling Conditions Used

\begin{tabular}{llll}
\hline \multicolumn{1}{c}{ Step } & Temperature $\left({ }^{\circ} \mathbf{C}\right)$ & Time & Number of Cycles \\
\hline Initial denaturation & 94 & 5 minutes & 1 \\
Denaturation & 94 & $30 \mathrm{sec}$ & 35 cycles \\
Annealing & $68(\mathrm{SHV})$ & $1 \mathrm{mins}$ & 1 \\
& $55(\mathrm{TEM})$ & & \\
& $60(\mathrm{CTX}-\mathrm{M})$ & & \\
& $50(\mathrm{OXX})$ & & \\
& $65(\mathrm{PER})$ & & 1 \\
& $65(\mathrm{VEB})$ & & 1 \\
Extension & 72 & 1 mins & \\
Final extension & 72 & 7 mins & \\
\hline
\end{tabular}

Key: SHV (Sulfhydryl variable), TEM (Temoneira), CTX-M (Cefotaxime hydrolyzing), OXA (Oxacillin hydrolyzing).

\section{Agarose Gel Electrophoresis of the PCR products}

One percent (1\%) Agarose gel (AG) was used to resolve the genomic DNA extracted from the $E$. coli isolates and documented. Preparation of the AG was carried out using $1 \mathrm{~g}$ of agarose in $90 \mathrm{ml}$ distilled water and heated for 2 minutes using a microwave. Before the heated AG cools, $2.5 \mathrm{ml}$ ethidium bromide $(5.0 \mathrm{mg} / \mathrm{ml})$ was added and the solution was swirled so it could mix properly. Using an electrophoretic tank and its comb, the gel was casted and allowed to solidify for 30 minutes, thereafter, the comb was removed and a TAE electrophoresis buffer (1X) added to the tank to cover the AG.
A $5 \mu$ l bromophenol blue was then mixed with $15 \mu \mathrm{l}$ of the extracted genomic DNA and loaded onto the wells of the solidified gel before the electrodes were connected and ran for 45 minutes at $100 \mathrm{mV}$. The product was removed from the tank and viewed under a $302 \mathrm{~nm}$ Transilluminator, Polaroid camera and a gel documentation system.

\section{Results}

Specimen Collection

A total of 170 mild stream urine samples submitted to the Medical Microbiology 
Laboratories of 4 different hospitals and that of healthy individuals were randomly collected for 5 months and examined for microbial growth as shown in Table 4. General Hospital Minna (67) had the highest urine samples followed by
Standard Hospital (30) and IBB Specialist Hospital (30) while the Hospital with the least samples was Top Medical Clinic (23). However, only 20 healthy individuals gave their consent and submitted samples for evaluation.

Table 4: Distribution of Samples collected from Four Hospitals and Healthy Individual

\begin{tabular}{lll}
\hline $\mathbf{S} / \mathbf{N}$ & Hospital & $\begin{array}{l}\text { Number of Urine } \\
\text { Samples collected }\end{array}$ \\
\hline 1 & ST & 30 \\
2 & IBB & 30 \\
3 & GH & 67 \\
4 & TMED & 23 \\
5 & HI & 20 \\
\hline Total & & $\mathbf{1 7 0}$ \\
\hline
\end{tabular}

Key: ST: Standard Hospital, IBB: IBB Specialist Hospital, GH: General Hospital, TMED: Top $\quad$ Medical Clinic, HI: Healthy Individuals

From the sample distributions, female patients (65.9\%) submitted more urine samples for UTI test to the Medical Laboratory of the Hospitals sampled compared to their male counterpart (34.1\%) (Table 5). Ages between 21 -30 (26.5\%) and 31 - 40 (25.3\%) had the highest percentages of infection rate while those within the ages 1-10 $(3.5 \%)$ and $\geq 71(2.3 \%)$ were the least infected (Table 6).

Table 5: Gender Distribution of Urine Samples from Four Hospitals and Healthy Individuals.

\begin{tabular}{|c|c|c|c|}
\hline \multirow[t]{2}{*}{ Hospital } & \multicolumn{2}{|c|}{ Gender (No and \% of Sample Collected) } & \multirow{2}{*}{$\begin{array}{l}\text { Total (\%) } \\
100 \%\end{array}$} \\
\hline & Male (\%) & Female (\%) & \\
\hline ST HOSP & $10(33.3)$ & $20(66.67)$ & $30(17.6)$ \\
\hline IBB HOSP & $10(33.3)$ & $20(66.67)$ & $30(17.6)$ \\
\hline $\mathrm{GH}$ & $21(31.34)$ & $46(68.66)$ & $67(39.4)$ \\
\hline TMED & $9(39.13)$ & $14(60.87)$ & $23(13.5)$ \\
\hline $\mathrm{HI}$ & $8(40)$ & $12(60)$ & $20(11.8)$ \\
\hline Total & $58(34.1)$ & $112(65.9)$ & 170(100) \\
\hline
\end{tabular}

Keys: ST: Standard Hospital, IBB: IBB Specialist Hospital, GH: General Hospital, TMED: Top Medical, H: Healthy Individuals 
Table 6: Age Distribution of Urine Samples Collected from Four Hospitals and Healthy Individual

\begin{tabular}{lllllll}
\hline AGE RANGE & IBB & ST & GH & TMED & HI & Total (\%) \\
\hline $1-10$ & 0 & 2 & 3 & 1 & 0 & $6(3.5)$ \\
$11-20$ & 2 & 4 & 6 & 5 & 2 & $19(11.2)$ \\
$21-30$ & 9 & 6 & 15 & 7 & 8 & $45(26.5)$ \\
$31-40$ & 5 & 6 & 20 & 8 & 4 & $43(25.3)$ \\
$41-50$ & 6 & 5 & 6 & 0 & 3 & $20(11.8)$ \\
$51-60$ & 5 & 5 & 10 & 1 & 1 & $22(12.9)$ \\
$61-70$ & 3 & 0 & 5 & 1 & 1 & $10(5.9)$ \\
$\geq 71$ & 0 & 2 & 2 & 0 & 0 & $4(2.3)$ \\
\hline Total & $\mathbf{3 0}$ & $\mathbf{3 0}$ & $\mathbf{6 7}$ & $\mathbf{2 3}$ & $\mathbf{2 0}$ & $\mathbf{1 7 0 ( 1 0 0 )}$ \\
\hline
\end{tabular}

Keys: ST: Standard Hospital, IBB: IBB Specialist Hospital, GH: General Hospital, TMED: Top Medical, H: Healthy Individuals

\section{Isolation and Identification of Escherichia coli}

The prevalence of $E$. coli in Minna metropolis was $23.5 \%$. Significant numbers $(30 \%)$ of healthy individuals $(\mathrm{HI})$ were observed to also harbor $E$. coli in their urine. IBB Specialist hospital had the highest percentage (36.7\%) of E.coli isolated from urine samples indicating a high UTI infection rate amongst the patients, followed by Standard Hospital (26.7\%) and General Hospital (20.9) while the hospital with the least number of patients that are infected with UTI was the Top Medical Hospital (Table 7).

Table 7: Distribution of E. coli Isolated from the Four Selected Hospitals and Healthy Individuals

\begin{tabular}{llll}
\hline Hospital & Samples Collected & $\boldsymbol{E}$. coli isolated & Percentage of $\boldsymbol{E}$. coli \\
\hline ST & 30 & 8 & 26.7 \\
IBB & 30 & 11 & 36.7 \\
GH & 67 & 14 & 20.9 \\
TMED & 23 & 1 & 4.3 \\
HI & 20 & 6 & 30 \\
\hline Total & $\mathbf{1 7 0}$ & $\mathbf{4 0}$ & $\mathbf{2 3 . 5}$ \\
\hline
\end{tabular}


Key: ST: Standard Hospital, IBB: IBB Specialist Hospital, GH: General Hospital, TMED: Top Medical, HI: Healthy Individuals

\section{Antibiotic Susceptibility Test}

The study observed significant susceptibility to Gentamicin (65\%), Ofloxacin (65\%), Tetracycline $(62.5 \%)$, Cotrimoxazole $(62.5 \%)$, and Streptomycin (57.5\%). Mildly susceptible to Augmentin (50\%), Amoxicillin (45\%), Pefloxacin
(37.5\%), Chloramphenicol (37.5\%), and Ciprofloxacin (35\%). High resistant profile was observed against all the betalactams tested [Cefuroxime (80\%), Amoxicillin (42.5\%), Augmentin (40), Cefotaxime (20\%) and Ceftaxidime (7.5\%)] (Figure 2).

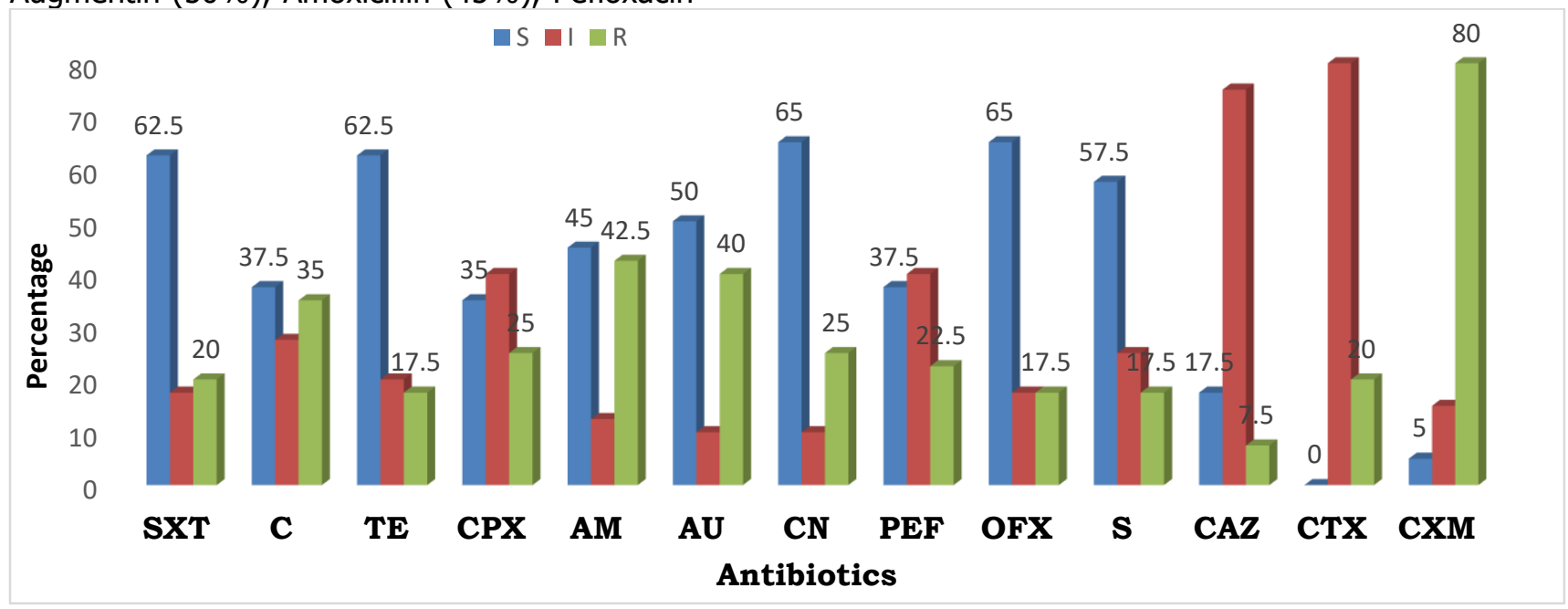

Figure 2: Percentage Antibiotics Susceptibility Profile of E. coli Isolated from UTI patients in Minna, Nigeria

Keys: SXT $=$ Cotrimoxazole, $\mathrm{C}=$ Chloramphenicol, $\mathrm{TE}=$ Tetracycline, $\mathrm{CPX}=$ Ciprofloxacin, $\mathrm{AM}=$ Amoxicillin, $\mathrm{AU}=$ Augmentin, $\mathrm{CN}=$ Gentamicin, $\mathrm{PEF}=$ Pefloxacin, OFX = Ofloxacin, $\mathrm{S}=$ Streptomycin, $\mathrm{CAZ}$ $=$ Ceftaxidime, $\mathrm{CTX}=$ Cefotaxime, $\mathrm{CXM}=$ Cefuroxime, $\mathrm{S}=$ sensitive $\mathrm{I}=$ intermediate $\mathrm{R}=$ resistance

Two of the isolates (U59 and U26) were resistant to all the 13 antibiotics tested; seventy percent (28) of the isolates had multiple antibiotics resistance index (MARI) $\geq 0.3$ while $30 \%$ (12) had $\leq 0.2$. The most common resistant pattern observed in $65 \%$ (26) of the isolates was simultaneous resistance to Ceftaxidime, Cefotaxime, and Cefuroxime (resistant to the Cephalosporin tested), while $20 \%$ (8) were resistant to all the beta lactams tested. Multiple drug resistance ( $\geq 3$ classes) was expressed in
$37.5 \%$ of the isolates tested. This study showcases a vast resistant pool in the environment where the study was conducted and possibility of beta lactamase production in the evaluated E. coli isolates. Resistance to all the 6 classes of antibiotic tested in 2 isolates from the different patient samples might indicate a plasmid profile encoding diverse genes of resistance or biofilm formation. However, extended spectrum beta-lactamase producing isolates have been reported to develop resistance to arrays of antibiotics commonly consumed in the environment (Table 8).

Table 8: Determination of Resistant Pattern and Multiple Antibiotic Resistant Index of the E. coli Isolated from UTI Patients in Minna, Niger State.

\section{S/N ISOLATE CODE \\ RESISTANT PATTERN}

NCART NART MARI 
Isegohi et al./ Nig. J. Biotech. Vol. 37 Num. 2: 56-73 (Dec 2020)

\begin{tabular}{|c|c|c|c|c|c|}
\hline 1 & U123 & $\mathrm{C}, \mathrm{AM}, \mathrm{AU}, \mathrm{CAZ}, \mathrm{CTM}$ & 2 & 5 & 0.4 \\
\hline 2 & U19 & $\mathrm{C}, \mathrm{TE}, \mathrm{CPX}, \mathrm{AM}, \mathrm{AU}, \mathrm{CN}, \mathrm{PEF}, \mathrm{OFX}, \mathrm{S}, \mathrm{CAZ}, \mathrm{CTX}, \mathrm{CXM}$ & 6 & 12 & 0.9 \\
\hline 3 & HU10 & $\mathrm{CAZ}, \mathrm{CXM}$ & 1 & 2 & 0.2 \\
\hline 4 & U41 & $\mathrm{AM}, \mathrm{PEF}, \mathrm{CAZ}, \mathrm{CTX}, \mathrm{CXM}$ & 2 & 5 & 0.4 \\
\hline 5 & U55 & $\mathrm{S}, \mathrm{CTX}$ & 2 & 2 & 0.2 \\
\hline 6 & U16 & $\mathrm{C}, \mathrm{AM}, \mathrm{AU}, \mathrm{CAZ}, \mathrm{CTX}, \mathrm{CXM}$ & 2 & 6 & 0.5 \\
\hline 7 & U59 & SXT,C,TE,CPX,AM,AU,CN,PEF,OFX,S,CAZ,CTX,CXM & 6 & 13 & 1 \\
\hline 8 & U53 & $\mathrm{C}, \mathrm{CAZ}, \mathrm{CTX}, \mathrm{CXM}$ & 2 & 4 & 0.3 \\
\hline 9 & U37 & CPX,AM,AU,PEF,CAZ,CTX,CXM & 2 & 7 & 0.5 \\
\hline 10 & U26 & SXT,C,TE,CPX,AM,AU,CN,PEF,OFX,S,CAZ,CTX,CXM & 6 & 13 & 1 \\
\hline 11 & U13 & $\mathrm{C}, \mathrm{CAZ}, \mathrm{CTX}, \mathrm{CXM}$ & 2 & 4 & 0.3 \\
\hline 12 & HU21 & AM,AU,OFX & 2 & 3 & 0.2 \\
\hline 13 & U50 & $\mathrm{TE}, \mathrm{CPX}$ & 2 & 2 & 0.2 \\
\hline 14 & U7 & $\mathrm{TE}, \mathrm{AM}, \mathrm{AU}, \mathrm{OFX}$ & 3 & 4 & 0.3 \\
\hline 15 & U64 & $\mathrm{AU}, \mathrm{CAZ}, \mathrm{CTX}, \mathrm{CXM}$ & 2 & 4 & 0.3 \\
\hline 16 & HU5 & $\mathrm{AU}, \mathrm{CN}, \mathrm{CTX}, \mathrm{CXM}$ & 2 & 4 & 0.3 \\
\hline 17 & U47 & $\mathrm{C}, \mathrm{CPX}, \mathrm{AM}, \mathrm{AU}, \mathrm{CN}$ & 4 & 5 & 0.4 \\
\hline 18 & HU18 & SXT, CAZ,CTX,CXM & 2 & 4 & 0.3 \\
\hline 19 & U70 & SXT,AM,CN,CTX,CXM & 3 & 5 & 0.4 \\
\hline 20 & U88 & SXT,AM,AU,CN, CAZ,CTX,CXM & 3 & 7 & 0.5 \\
\hline 21 & U139 & $\mathrm{C}, \mathrm{TE}, \mathrm{AM}, \mathrm{S}, \mathrm{CAZ}, \mathrm{CTX}, \mathrm{CXM}$ & 4 & 7 & 0.5 \\
\hline 22 & U111 & SXT, OFX,S,CAZ,CTX,CXM & 4 & 6 & 0.5 \\
\hline 23 & U102 & $\mathrm{AM}, \mathrm{AU}, \mathrm{CN}, \mathrm{S}, \mathrm{CAZ}, \mathrm{CTX}, \mathrm{CXM}$ & 4 & 7 & 0.5 \\
\hline 24 & U82 & $\mathrm{AM}, \mathrm{AU}, \mathrm{CTM}$ & 2 & 3 & 0.2 \\
\hline 25 & U71 & SXT,C,AM, CAZ,CTX,CXM & 3 & 6 & 0.5 \\
\hline 26 & U134 & CN,PEF, CAZ,CTX,CXM & 3 & 5 & 0.4 \\
\hline 27 & u65 & $\mathrm{CAZ}, \mathrm{CTX}, \mathrm{CXM}$ & 1 & 3 & 0.2 \\
\hline 28 & U46 & CXM & 1 & 1 & 0.1 \\
\hline 29 & U58 & CPX,AM, CAZ,CTX,CXM & 2 & 5 & 0.4 \\
\hline 30 & U60 & PEF, CAZ,CTX,CXM & 2 & 4 & 0.3 \\
\hline 31 & U30 & $\mathrm{CAZ}, \mathrm{CTX}, \mathrm{CXM}$ & 1 & 3 & 0.2 \\
\hline 32 & U44 & CAZ,CTX,CXM & 1 & 3 & 0.2 \\
\hline 33 & U155 & C,PEF, CAZ,CTX,CXM & 3 & 5 & 0.4 \\
\hline 34 & U61 & CPX,PEF, CAZ,CTX,CXM & 2 & 5 & 0.4 \\
\hline 35 & U155 & $\mathrm{CAZ}, \mathrm{CTX}, \mathrm{CXM}$ & 1 & 3 & 0.2 \\
\hline 36 & U61 & SXT,C,CPX,AM,AU,OFX, CAZ,CTX,CXM & 4 & 9 & 0.7 \\
\hline 37 & U56 & AU,CAZ & 1 & 2 & 0.2 \\
\hline 38 & U15 & $\mathrm{C}, \mathrm{TE}, \mathrm{CPX}, \mathrm{CAZ}, \mathrm{CXM}$ & 4 & 5 & 0.4 \\
\hline 39 & U63 & C, CAZ,CTX,CXM & 2 & 4 & 0.3 \\
\hline 40 & U18 & CTX,CXM & 1 & 2 & 0.2 \\
\hline
\end{tabular}

Keys: NCART $=$ number of classes of antibiotics resistant to, NARI $=$ number of antibiotics resistant to, MARI $=$ multiple antibiotics resistance index, $\mathrm{SXT}=$ Cotrimoxazole, $\mathrm{C}=$ Chloramphenicol, $\mathrm{TE}=$ Tetracycline, 
$\mathrm{CPX}=$ Ciprofloxacin, $\mathrm{AM}=$ Amoxicillin, $\mathrm{AU}=$ Augmentin, $\mathrm{CN}=$ Gentamicin, $\mathrm{PEF}=$ Pefloxacin, $\mathrm{OFX}=$ Ofloxacin, $\mathrm{S}=$ Streptomycin, $\mathrm{CAZ}=$ Ceftaxidime, $\mathrm{CTX}=$ Cefotaxime, $\mathrm{CXM}=$ Cefuroxime

Plate A shows a significant extended spectrum of activity of amoxicillin/clavulanic acid to the Cephalosporins placed $15 \mathrm{~mm}$ apart from its center, and all the beta-lactams tested had $\geq 5 \mathrm{~mm}$ zones of inhibition compared to when tested alone. In Plate $B$ there was only an extended spectrum of the amoxicillin/clavulanic acid to ceftaz idime with reduced zone of inhibition while cefpodoxime and cefotaxime had no zones of inhibitions [Plate I].

Presumptive Test for Extended Spectrum Beta Lactamase (ESBL) Production

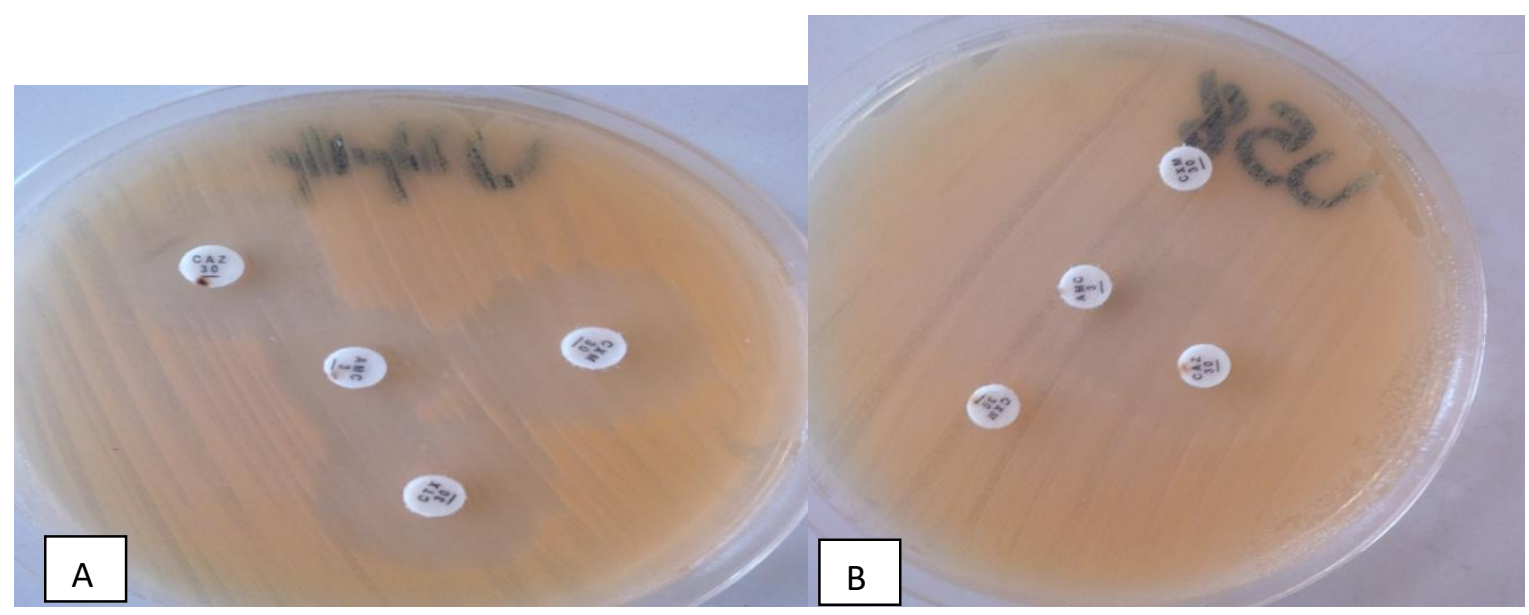

Plate I: Pictorial Representation of Expressed Extended Spectrum $\beta$ - Lactamase Producing Isolates of $E$. coli.

Keys: Plate A showed the production of ESBL (positive result). Plate B showed no production of ESBL (negative result). - (negative); + (positive); AMC (amoxicillin-clavulanate); CAZ (ceftazidime), CXM (cefuroxime); CTX (cefotaxime), U (urine), HU (healthy urine).

Significant percentage $(25 \%)$ of the E. coli isolated from the Urine samples, expressed the phenotypic ability to produce beta-lactamases while $75 \%$ were none ESBL producers (Figure 3)

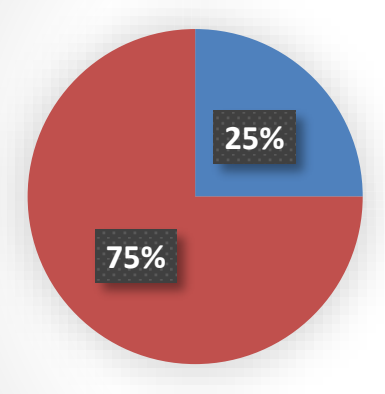

ESBL Producers

none ESBL Producers

Figure 3: Evaluation for ESBL Production among E. coli Isolated from UTI Patients in Minna, Nigeria

Table 9 shows that all the ESBL- producing isolates were resistant to more than 5 antibiotics tested and had a MAR Index of $\geq 0.5$, while $90 \%$ showed multiple drug resistance ( $\geq 3$ classes).
Further evaluation showed that 25\% (10/40) of the $E$. coli isolated from UTI patients in Minna, Nigeria were ESBL producers and could harbor one or two of the genes. This implies that only 
$5.9 \%$ of the urine samples had ESBL- encoding E. coli with multidrug resistance characteristics.

Table 9: Antibiotics Susceptibility Profile of ESBL Producing E. coli isolated from UTI patients in Minna, Nigeria

\begin{tabular}{llllll}
\hline S/N & $\begin{array}{l}\text { ISOLATE } \\
\text { CODE }\end{array}$ & RESISTANT PATTERN & NCART & NART & MARI \\
\hline 1 & U19 & C,TE,CPX,AM,AU,CN,PEF,OFX,S,CAZ,CTX,CXM & 6 & 12 & 0.9 \\
2 & U59 & SXT,C,TE,CPX,AM,AU,CN,PEF,OFX,S,CAZ,CTX,CXM & 6 & 13 & 1 \\
3 & U37 & CPX,AM,AU,PEF,CAZ,CTX,CXM & 2 & 7 & 0.5 \\
4 & U26 & SXT,C,TE,CPX,AM,AU,CN,PEF,OFX,S,CAZ,CTX,CXM & 6 & 13 & 1 \\
5 & U88 & SXT,AM,AU,CN, CAZ,CTX,CXM & 3 & 7 & 0.5 \\
6 & U139 & C,TE,AM,S,CAZ,CTX,CXM & 4 & 7 & 0.5 \\
7 & U111 & SXT, OFX,S,CAZ,CTX,CXM & 4 & 6 & 0.5 \\
8 & U102 & AM,AU,CN, S,CAZ,CTX,CXM & 4 & 7 & 0.5 \\
9 & U71 & SXT,C,AM, CAZ,CTX,CXM & 3 & 6 & 0.5 \\
10 & U61 & SXT,C,CPX,AM,AU,OFX, CAZ,CTX,CXM & 4 & 9 & 0.7 \\
\hline
\end{tabular}

Keys: NCART $=$ number of classes of antibiotics resistant to, NARI $=$ number of antibiotics resistant to, MARI $=$ multiple antibiotics resistance index, SXT $=$ Cotrimoxazole,$C=$ Chloramphenicol, $T E=$ Tetracycline, $\mathrm{CPX}=$ Ciprofloxacin, $\mathrm{AM}=$ Amoxicillin, $\mathrm{AU}=$ Augmentin, $\mathrm{CN}=$ Gentamicin, $\mathrm{PEF}=$ Pefloxacin, $\mathrm{OFX}=$ Ofloxacin, $\mathrm{S}=$ Streptomycin, $\mathrm{CAZ}=$ Ceftaxidime, $\mathrm{CTX}=$ Cefotaxime, $\mathrm{CXM}=$ Cefuroxime

Molecular Characterization of ESBL Resistant Escherichia coli

The genomic DNA of the 10 samples that were resistant to all the tested beta-lactams and exhibited presumptive ESBL were extracted. The evaluation showed that all the isolates harbor one or two genes harboring the ESBL enzyme. TEM gene of $931 \mathrm{bp}$ was expressed in $70 \%$ (7) of the isolates, $60 \%$ (6) harbored CTXM gene that amplified at 593bp, 20\% (2) had the OXA gene which is $478 \mathrm{bp}$ while none of the bacteria harbored the SHV gene (Plate II).

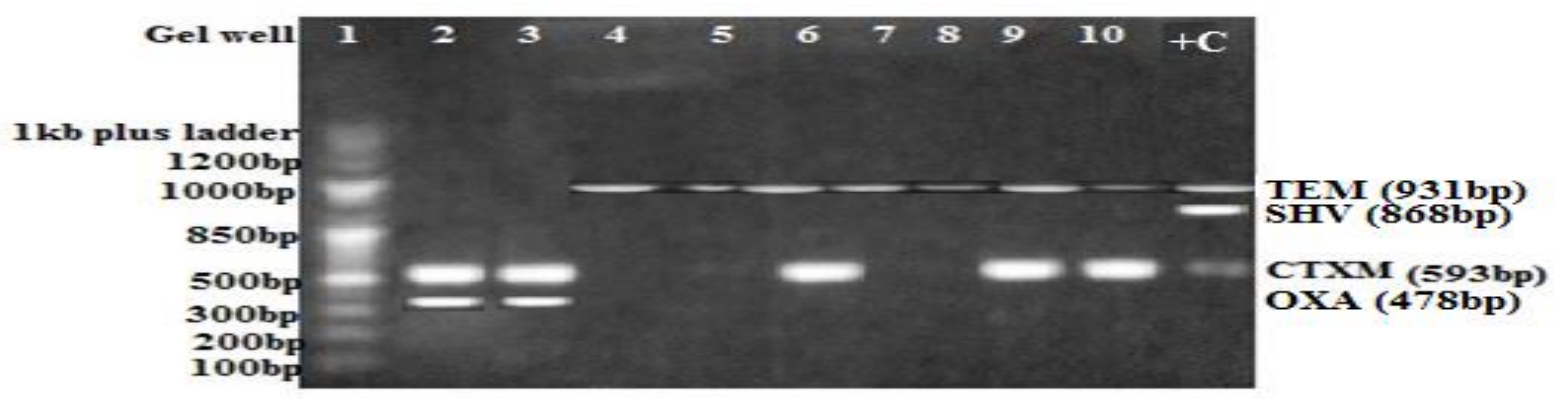

Plate II: Electrophoregraph of ESBL producing E. coli isolated from Urine samples of UTI patients in Minna, Nigeria

Keys: $1=$ DNA ladder, $2=\mathrm{U19}, 3=\mathrm{U} 59,4=\mathrm{U} 37,5=\mathrm{U} 26,6=\mathrm{U} 88,7=\mathrm{U} 111,8=\mathrm{U} 102,9=\mathrm{U71}, 10=$ $\mathrm{U} 61,+\mathrm{C}=$ E. coli ATCC25922

\section{Discussion}


Studies have shown that UTI is generally caused by bacterial proliferation within the urinary tract in both males and females. Escherichia coliassociated UTI accounts for one of the most major causes of hospital visits (Flores-Mireles et al., 2015). This bacterium has also been implicated in most infections, including cholecystitis, bacteremia, cholangitis, and diarrhea (Dong et al., 2018). To achieve effective therapeutic outcome, the causative microorganism must be characterized and an antibiogram conducted to determine the most potent antibiotics (Igwe et al., 2014).

From the sample distribution, female patients $(65.9 \%)$ suffered more UTI compared to their male counterpart (34.1\%). This observation correlates with other reports who also observed that female patients are more prone to UTI than males (Rajalakshmi and Amsaveni, 2012; Sood and Gupta, 2012; Idakwo et al., 2015). This might be due to women anatomy and reproductive physiology i.e. proximity of female urethral opening to the anus. More so, the female urethra is shorter than the male's; this enables easy bacteria access to the bladder. Our study also observed that age ranges of $21-30$ $(26.5 \%)$ and $31-40(25.3 \%)$ had the highest percentages of infection rate while those within the ages of $1-10(3.5 \%)$ and $\geq 71(2.3 \%)$ were the least infected. These findings tally with the study conducted by Idakwo et al., (2015) in Minna, of which patients within the age groups of 20 - 29 years were the most infected. According to Dielubenza and Schaeffer, (2011), high sexual activity, the use of a diaphragm with spermicide, childbirth, menopause in such age limit are among the predisposing factors to infections.

The prevalence of $E$. coli- associated UTI in Minna metropolis as observed in this study was $23.5 \%$. This result tallies with the report of Omonigho et al., (2001), who observed a prevalence of $22.3 \%$ but lower than the reports of Idakwo et al., (2015), Ebie et al., (2001) and Oladeinde et al., (2011) who recorded $32.5 \%$ in Minna, Niger State, $35.3 \%$ in Offa, Kwara State and $39.7 \%$ in Okada, Edo state, respectively. Comparative evaluation of bacte ria in UTI revealed that Escherichia coli prevalence varies from $20 \%$ to $85 \%$ in most UTI studies (Vasudevan, 2014). This might be attributed to age, parity, gravidity, and other associated diseases, which might augment the condition (Vasudevan, 2014). Urinary tract infection is not only caused by $E$. coli bacteria but also other pathogens such as Staphylococcus aureus, Klebsiella spp., Proetus vulgaris, Pseudomonas aeruginosa and Salmonella spp. (Oladeinde et al., 2011).

Significant numbers (30\%) of healthy individuals $(\mathrm{HI})$ were observed to also harbor $E$. coli in their urine. This is termed asymptomatic bacteri uria $(A B U)$ : a commensal condition where the patients carry $>10^{5} \mathrm{CFU} / \mathrm{ml}$ of the bacteria without any symptom (Salvador et al., 2012). This strain of UTI $E$. coli has been studied to evolve from virulent uropathogenic $E$. coli strains, which had developed significant mechanisms of bacterial adaptation that enables its prototype (ABU strain Escherichia coli 83972) to evolve a smaller genome than uropathogenic $E$. coli (UPEC) strains. A study on the bacteria had shown point mutations or deletions in most of the virulence genes encoded by the bacteria. This further highlights that $A B U$ strains are subject to evolutionary transformation within its hosts (Zdziarski et al., 2008). According to Salvador et al., (2012), ABU strains can evolve in 2 to $20 \%$ of the population for months or years and it is influenced by factors such as gender and age.

The isolates had varying susceptibility patterns but were more susceptible to Gentamicin, Ofloxacin, Tetracycline, Cotrimoxazole, and Streptomycin. According to Hattewar et al., (2020), most of these antibiotics are considered as appropriate antimicrobials for empirical treatment of urinary tract infections in most clinics, especially in developing countries. The isolates were mildly susceptible to Augmentin, Amoxicillin, Pefloxacin, Chloramphenicol and Ciprofloxacin. High resistance was observed against all the beta-lactams tested [Cefuroxime, Amoxicillin, Augmentin, Cefotaxime and Ceftaxidime]. The differences in drug resistance by the isolates in this study correlate with the findings documented by Onifade et al., (2015) and Lohani et al., (2020). Most of their E. coli isolates expressed significant resistance to Trimethoprim, Ceftazidime, Gentamicin, Cefuroxime, Chloramphenicol, Cefixime, Augmentin and Tetracycline but showed mild susceptibility to Quinolones and Nitrofurantoin. Two of the isolates were resistant to all the 13 
antibiotics tested while $70 \%$ of the isolates had multiple antibiotics resistance index $(M A R I) \geq 0.3$. The isolates had a consistent resistant pattern in $65 \%$ of their population. This study showcases a vast resistant pool in the environment where the study was conducted and the possibility of betalactamase production in the evaluated $E$. coli isolates. The study conducted by Ochada et al., (2015) further buttresses the fact that $E$. colifrom UTI show a pattern of resistance depending on the tested antibiotics. Resistance to all the 6 classes of antibiotics tested in 2 isolates from the different patients sampled might indicate a plasmid profile encoding diverges genes of resistance or biofilms. However, extended spectrum beta-lactamase- producing isolates have been reported to develop resistance to arrays of antibiotics commonly consumed in an environment.

Our study showcases the possibility of better chemotherapeutic outcome of urinary tract infections using Quinolones and Nitrofurantoin even in the presence of multidrug resistance. This is very crucial as total lack of hope on the commonly prescribed antibiotics spontaneously aggravates poor life quality and expectancy, which further materializes to death. However, this study calls for more periodic surveillance on antibiograms as this will influence the use of appropriate antimicrobial agents.

As discussed in other studies, the evaluation of drug resistant isolates are primarily conducted using molecular genotyping and phenotyping techniques, which are deployed in screening and to confirm expression of antimicrobial drug resistance genes within a population (Alyamani et al., 2017). This was carried out among suspected extended spectrum beta- lactamase (ESBL)producing Escherichia coli known to be one of the leading causes of deaths globally among UTI patients, as this strain harbors multidrug resistance and virulent genes (Ramadan et al., 2019). In this study, $25 \%$ (5.9\% of the total urine samples), expressed the phenotypic ability to produce beta-lactamase enzymes. Examination of these isolates shows that $70 \%$ (7) [i.e. $17.5 \%$ of the total E. coli] harbors the TEM gene; $60 \%$ (6) [i.e. 15\%] harbored CTXM gene; $20 \%$ (2) [i.e. $5 \%$ ] had the OXA gene while none of the bacteria had the SHV gene. Further empirical study showed that $90 \%$ of the ESBLproducing isolates were multidrug resistant and had MARI of $\geq 0.5$. This study is similar to the findings of Ejikeugwu et al., (2013) who reported $27.7 \%$ of ESBLs in Enugu and $26.1 \%$ in Ile-Ife by Olufunke et al., (2014). However, the prevalence of ESBL is geographically dependent. This is linked to the variability in the use of antimicrobiasl and measures put in place to control infections in these locations (Rapp, 2011). The study conducted by Yasir et al., (2018) also established that most ESBL isolates are multidrug resistant (MDR), especially to $3^{\text {rd }}$ and $4^{\text {th }}$ generation cephalosporins. Most worrisome was the reports of Shakil et al., (2010) and Ny et al., (2017), which revealed that ESBLs are harbored among asymptomatic community dwellers and are often plasmid-associated, with the ability of cross-species dissemination and multidrug resistance genes that encode fluoroquinolones, aminoglycosides, tetracycline's, cotrimoxazole and chloramphenicol.

\section{Conclusion and Recommendations}

This study showed a prevalence of $23.5 \%$ E. coliassociated UTI in Minna, Nigeria and further established the presence of ESBL in $5.9 \%$ of the isolates with multidrug resistance characteristics. Drugs of choice which could be used for their treatment were Gentamicin, Ofloxacin, Tetracycline, Cotrimoxazole, and Streptomycin. It further substantiated the importance of good antibiogram evaluation as it establishes a baseline for empirical diagnosis, epidemiological surveillance, drug prescription and infection management.

\section{References}

Abrar, S., Ain, N. U., Liaqat, H., Hussain, S., Rasheed, F., and Riaz, S. (2019). Distribution of blactх-м , blaтем, blasнv and blaoxa genes in Extended-spectrum- $\beta$-lactamase-producing Clinical isolates: A three-year multi-center study from Lahore, Pakistan. Antimicrobial resistance and infection control, 8, 80.

Ahmed S.M. and Avasara A.K. (2009). Urinary tract infections (UTI) among adolescent girls in rural Karimnagar District. Indian J Pre Soc Med. 39(1 \& 2). 
Alyamani E. J., Khiyami A. M., Booq R. Y., Majrashi A., Bahwerth F. S., and Rechkina E. (2017). "The occurrence of ESBLproducing Escherichia coli carrying aminoglycoside resistance genes in urinary tract infections in Saudi Arabia," Annals of Clinical Microb. and Ant., 16(1):1-13.

Baziboroun M, Bayani M, Poormontaseri Z, Shokri M, Biazar T (2018). Prevalence and Antibiotic Susceptibility Pattern of Extended Spectrum Beta Lactamases Producing Escherichia Coli Isolated from Outpatients with Urinary Tract Infections in Babol, Northern of Iran. Current Issues in Pharm. and Med. Sci. 31(2).

Cheesbrough M (2010). District laboratory practice in tropical countries, Part 2. 2nd Edition update. Cambridge University Press, Cambridge, United Kingdom. Pp 107-114.

Center for disease control (CDC) (2019). Urinary Tract Infection. https://www.cdc.gov/antibioticuse/community/for-patients/commonillnesses/uti.html

Clinical and Laboratory Standards Institute (CLSI) (2016): Performance standards for antimicrobial susceptibility testing; Twenty-sixth informational supplement. CLSI document M100-S26. Wayne, PA: Clinical and Laboratory Standards Institute.

Dechen C.T, Shyamasree D, Luna A, Ranabir P, Takhellambam S.K.S. (2009). "Extended Spectrum Beta-lactamase Detection in Gramnegative Bacilli of Nosocomial Origin." J. Glob. Infec. Dis., 1 (2): 87-92.

Dhillon R.H and Clark J. (2012). ESBLs: A Clear and Present Danger?. Crit Care Res Pract., 2012:625170.

Dias CS, Silva JMP, Diniz JSS, Lima EM, Marciano RC, Lana LG, Trivelato ALL, Lima MS, e Silva ACS, Oliveira EA (2010). "Risk factors for recurrent urinary tract infections in a cohort of patients with primary vesicoureteral reflux," Pediatric Infect. Dis. J., 29 (2): 139-144.

Dielubenza E.J. and Schaeffer A.J. (2011). Urinary tract infections in women. The Medical clinics of North America, 95(1): 27-41
Dong S.L., Seung-Ju L. and Hyun-Sop Choe (2018). Community-Acquired Urinary Tract Infection by Escherichia coli in the Era of Antibiotic Resistance. Biomed Research International, 2018(1):1-15

Dougherty J.M., Rawla P. (2020). Female Urinary Retention. In: StatPearls [Internet]. Treasure Island (FL): StatPearls Publishing; 2020 JanAvailable from: https://www.ncbi.nlm.nih.gov/books/NBK53849 그

Dubey R. C. (2009). Multicolour Textbook of Biotechnology. $4^{\text {th }}$ Edition. India: S. Chand and Co.

Ebie M.Y., Kandaki-Olukemi Y.T., Ayanbadejo J, and Tanyigna K.B. (2001). UTI infections in a Nigerian Military Hospital. Nig. J. Microbiol. 15(1): 31-37

Ugwu M.C., Shariff M., Nnajide C.M., Beri K, Okezie U.M, Iroha I.R, Esimone C.O (2013). "Detection and antimicrobial susceptibility of some gram negative bacteria producing carbapenemases and extended spectrum $\beta$ Lactamases," International J. Microb. and Imm. Res., 2(6): 64-69

Falagas M.E. and Karageorgopoulos D.E. (2009). Extended-spectrum beta-lactamase-producing organisms. J Hosp Infect. 73(4):345-354.

Flores-Mireles, A. L., Walker, J. N., Caparon, M., \& Hultgren, S. J. (2015). Urinary tract infections: epidemiology, mechanisms of infection and treatment options. Nature reviews. Microb. 13(5), 269-284.

Hattewar J, Koul A and Mathur A (2020). Antibiotic susceptibility pattern of ESBL producing bacteria from urinary tract infection (UTI). Int J Pharm Sci \& Res; 11(2): 799-10

Hoberman A., Charron M., Hickey R. W., Baskin M., Kearney D. H., and Wald E. R. (2003). "Imaging studies after a first febrile urinary tract infection in young children," New England Journal of Medicine, 348(3): 195-202.

Idakwo S.O, Mawak J.D, Abalaka M.E (2015). Prevalence and Antibiogram of Urinary Tract Infections in Patients Attending Hospitals in 
Minna, Niger State. International Journal of Microbiology, Biochemistry, Molecular Biology, 1(1): 8-12

Igwe JC, Onaolapo JA, Kachallah M, Nworie A, Oladipo HO, Ojiego B, Enose OD, Adeboye SE, Durowaiye MT, Akpa A and Ibanga I (2014). Molecular characterization of extended spectrum $\beta$-lactamase genes in clinical $E$. coli isolates. J Biomed Sci Eng. 7(5):276-285

Jacoby GA and Munoz-Price LS (2005). The new beta-lactamases. N Engl J Med. 352(4):380-391.

Jombo GTA, Egah DZ, Ayeni JA (2006a). Antibiotic susceptibility patterns of bacterial isolates from urine samples of acquired immunodeficiency syndrome (AIDS) patients in Jos, Nigeria. Mary Slessor J. Med., 6(2): 40-49.

Krumperman, P H. (1983) "Multiple antibiotic resistance indexing of Escherichia coli to identify high-risk sources of fecal contamination of foods." Applied and Env. Mic. 46(1): 165-70.

Lane DR, Takhar SS (2011). Diagnosis and management of urinary tract infection and pyelonephritis. Emerg Med Clin North Am. 29(3):539-552. doi:10.1016/j.emc.2011.04.001

Lohani B, Thapa M, Sharma L, H Adhikari, AK Sah, Khanal AB, Basnet RB, Aryal M (2020). Predominance of CTX-M Type Extended Spectrum $\beta$-lactamase (ESBL) Producers Among Clinical Isolates of Enterobacteriaceae in a Tertiary Care Hospital, Kathmandu, Nepal. The Open Microb. J., 14: 13-22

Martin O, Adamu AA, Julius T, Josephat NM, Eddie W, Charles DK, Ezera A, and Joel B (2019). Prevalence of Bacterial Urinary Tract Infections and Associated Factors among Patients Attending Hospitals in Bushenyi District, Uganda. Int. J. Microb., 2019(1):1-9

Mehrgan H, Rahbar M. (2008) Prevalence of extended-spectrum beta-lactamase-producing Escherichia coli in a tertiary care hospital in Tehran, Iran. Int J Anti. Agents, 31(2):147-151.

Mirsoleymani SR., Salimi M, Shareghi MB, Ranjbar M, and Mehtarpoor M (2014). "Bacterial pathogens and antimicrobial resistance patterns in pediatric urinary tract infections: a four-year surveillance study (2009-2012)," Intern. J. Ped., 2014:1-8.

Monstein $\mathrm{HJ}$, Ostholm-Balkhed A, Nilsson MV, Dornbusch K and Nilsson LE (2007). Multiplex PCR amplification assay for the detection of blaSHV, blaTEM and blaCTX-M genes in Enterobacteriaceae. Acta Path. Microb. Imm. Scandinavia, 115(12), 1400-8.

Nelson J. M. and Good E (2015) "Urinary tract infections and asymptomatic bacteriuria in older adults," Nurse Pract., 40(8): 43-48, 2015.

Ny S, Löfmark S, Börjesson $S$, Englund $S$, Ringman $M$, Bergström J, Nauclér P, Giske PG, Byfors S (2017). Community carriage of ESBLproducing Escherichia coli is associated with strains of low pathogenicity: a Swedish nationwide study, J. Ant. Chem. 72(2):582-588

Ochada, NS., Nasiru, IA., Thairu, Y., Okanlowan M B., Abdulakeem, YO (2015). Antimicrobial Susceptibility Pattern Of Urinary Pathogens Isolated From Two Tertiary Hospitals In Southwestern Nigeria. Afr. J. Cln. Exper. Microbiol., 16(1): 12-22

Oladeinde BH, Omoregie R, Olley M, and Anunibe JA (2011). Urinary tract infection in a rural community of Nigeria. North Amer. J. Med. Sci. 3(2): 75-77.

Olufunke O. A., O. A. Aregbesola, and C. D. Fashina (2014). "Extended spectrum betalactamase- producing uropathogenic Escherichia coli in pregnant women diagnosed with urinary tract infections in south-western Nigeria," J. Mol. Bio. Res., 4(1): 34-42.

Omonigho SE, Obasi EE, Akukalia RN (2001). In vitro Resistance of Urinary Isolates of Escherichia coli and Klebsiella species to Nalidixic Acid. Niger. J. Microbiol. 15(1):25-29.

Onifade A.K, Oladoja M. A, Fadipe D, O (2015). Antibiotics sensitivity pattern of $E$. coli isolated from children of school age in Ondo state, Nigeria. Researcher, 7(2):73-76

Pandit R, Balkrishna A, Sumesh SS, Govardhan J, Basista PR and Narayan PP (2020). Extended- 
Spectrum $\beta$-Lactamase (ESBL) Genotypes among Multidrug-Resistant Uropathogenic Escherichia coli Clinical Isolates from a Teaching Hospital of Nepal. Interdisciplinary Perspectives on infectious diseases, 2020: 1-8

Papadimitriou-Olivgeris M, Drougka E, Fligou F, Kolonitsiou F, Liakopoulos A, Dodou V, Anastassiou ED, Petinaki E, Marangos M, Filos KS, Spiliopoulou I (2014). Risk factors for enterococcal infection and colonization by vancomycin-resistant enterococci in critically ill patients. Infection 42(6): 1013-1022.

Prakash D. and Saxena R. S. (2013). "Distribution and antimicrobial susceptibility pattern of bacterial pathogens causing urinary tract infection in Urban Community of Meerut City, India," ISRN Microbiology, 2013:1-3

Rajalakshmi V, and Amsaveni V (2012). Antibiotic susceptibility of bacterial pathogens isolated from diabetic patients. Int. J. Microbiol. Res. 3(1): 3032

Ramadan, A.A., Abdelaziz, N.A., Amin, M.A. Aziz RK (2019). Novel blaCTX-M variants and genotype-phenotype correlations among clinical isolates of extended spectrum beta lactamaseproducing Escherichia coli. Sci Rep 9, 4224

Rapp R. P. (2011). "Antimicrobial resistance and antibiogram evaluation: a new practitioner's preparation for antimicrobial stewardship," in Proceedings of the 2011 Midyear Clinical Meeting Presentation, American Society of Health-System Pharmacists, New Orleans, Louisiana, December 2011

Salvador, E., Wagenlehner, F., Köhler, C. D., Mellmann, A., Hacker, J., Svanborg, C., \& Dobrindt, U. (2012). Comparison of asymptomatic bacteriuria Escherichia coli isolates from healthy individuals versus those from hospital patients shows that long-term bladder colonization selects for attenuated virulence phenotypes. Infec. and Imm., 80(2): 668-678.

Sani A. R., Hussaini M., Baba J., Katako G. U. (2019). Bacterial Infection of the Urinary Tract and Glucose Level in Patients Presented with Urinary Tract Infection in General Hospital Minna, J. Microb. Res., 9(1):1-5.
Schechner V, Kotlovsky T, Kazma M, Mishali H., Schwartz D., Navon-Venezia S., Schwaber MJ, Carmeli Y, (2013). Asymptomatic rectal carriage of blaKPC producing carbapenem-resistant Enterobacteriaceae: who is prone to become clinically infected?. Clin Microbiol Infect., 19(5):451-456.

Shakil, S., Akram, M., Ali, S. M. \& Khan, A. U (2010). Acquisition of extended-spectrum betalactamase producing Escherichia coli strains in male and female infants admitted to a neonatal intensive care unit: molecular epidemiology and analysis of risk factors. J Med Microbio/ 59, 948954,

Sood S and Gupta R (2012). Antibiotic resistance pattern of community acquired uropathogens at a tertiary care hospital in Jaipur, Rajasthan. Indian J. Comm. Med. 37(1): 39-44

Vasudevan R (2014). Urinary tract infection: an overview of the infection and the associated risk factors. J Microb. Exp. 1(2):42-54

Wu. Y., Cheng, M., Lai, C., Lin, H., Hung, C., Wang, J (2014). The role of Sequence Type (ST) 131 in adult community-onset non-ESBLproducing Escherichia coli bacteraemia. BMC Infect. Dis. 14:579

Yasir, M., Ajlan, A.M., Shakil, S. Asif AJ, Saad BA, Muhammad F, Baazeem ZM, Baabdullah R, Alawi M, Al-Abdullah N, Ismaeel NA, Ismaeel NA, Shukri HA and Azhar EI (2018). Molecular characterization, antimicrobial resistance and clinico-bioinformatics approaches to address the problem of extended-spectrum $\beta$-lactamaseproducing Escherichia coli in western Saudi Arabia. Sci Rep 8, 14847

Zdziarski J, Svanborg C, Wullt B, Hacker J, Dobrindt $U$ (2008). Molecular basis of commensalism in the urinary tract: low virulence or virulence attenuation? Infect Immun., 76(2):695-703. 